\title{
Editorial
}

\section{Working conditions and sickness absence: the need for action oriented research}

Two important conclusions can be drawn from the study published by Vahtera et $a l^{1}$ in this issue of the journal: (a) workers' sickness absence is related to working conditions, and (b) improvements in psychosocial working conditions reduce the risk of illness among workers. The negative effects on health of inadequate working conditions have long been recognised. ${ }^{2}$ But frequently, such effects are only consciously perceived both by workers and society at large through their most obvious consequences: occupational injuries and occupational illnesses. However, less specific diseases, such as musculoskeletal disorders, accounting for a great number of sick leave episodes, are related to the working conditions as well, including psychosocial factors. ${ }^{3}$ Besides, if interventions in the workplace to reduce sickness absence are to be implemented, evidence of their positive effects on the workers' health and well being are required.

Certainly, sick leave will usually be the consequence of any medical condition affecting occupationally active people. Sickness absence is often narrowly considered by society and by many organisations and enterprises as a problem of economics, and specific management programmes devoted to control and reduce the number and the duration of sickness leaves among the employees are frequent. However, most of these programmes do not include proper assessment and intervention on the work environment factors related to sickness absence. Some policies to control sickness absence episodes have been particularly controversial, and the workers, their representatives and some health professionals have been against them. For example, in Spain a part of the medical scheme to control sickness absence has been transferred from the National Health System to the companies that manage economic and health consequences of occupational illnesses and injuries. ${ }^{4}$ As these companies are traditionally more prone to serve the employers' instead of the employees' interests, worries have been expressed among health professionals from the public system, afraid of a preeminence of economic over health concerns in the diagnosis, treatment and management of sick workers. ${ }^{5}$

If the relation between sickness absence and working conditions becomes widely recognised, a fertile field of action would emerge to prevent and reduce the economic and health impact of these episodes on workers, companies and society at large. In their detailed analysis of several psychosocial working conditions, Vahtera et $\mathrm{al}^{1}$ report that a combination of poor participation in decision making, poor skill discretion, high job demands and low job control could increase more than twice the risk for a sick leave in the workers. The relation between job strain and health has been repeatedly demonstrated, and job stress has even been suggested as a major contributor to the well known socioeconomic gradients in health, ${ }^{6}$ although not without controversy. ${ }^{7}$ In relation to this, the study by Vahtera et al raises two specially relevant issues: (a) workers' sick leaves could be prevented through specific improvements in the psychosocial working environment; and (b) the association of psychosocial factors at work with more specific health indicators could be significantly stronger than reported, as this study was focused on a relatively crude health indicator such as all causes sickness absence.

On the other hand, health problems are often simply imputed to individual behavioural risk factors, such as smoking, alcohol consumption, sedentariness or overweight, and this is frequently the case for injured and diseased workers as well, including unsafe behaviours in the performance of their job tasks. None the less, in the Finnish study adjustments for behavioural and biological risk factors did not change significantly the association between psychosocial job characteristics and sick leave. ${ }^{1}$ Moreover, job strain has been positively associated with smoking, smoking intensity, high fat intake and low exercise in other studies. $^{8}$

The study by Vahtera et al also allows identification of specific psychosocial factors (and their combinations) predicting the highest increases in the risk of illness among the workers. Increasing job control (worker's control over the use of skills on the job, worker's authority to make decisions about the organisation of their work, or worker's ability to exert control over uncertainties at work), together with high or improved supervisory support, are shown in the article to significantly reduce the risk of sick leave among the workers. As the authors suggest, this finding could have practical implications for innovation in the design and management of preventive interventions for sickness absence in the workplace. Interventions to improve workers' health should be based on the best available scientific evidence. Unfortunately, good scientific evidence is often conspicuously lacking in occupational health. The results reported by Vahtera et al point clearly to some specific psychosocial determinants of workers' illness, and it would be interesting to know the results of rigorous research assessing the effects upon sickness absence rates of intervention programmes in the workplace acting on these determinants.

Psychosocial work environment and job strain were the focus in this study. ${ }^{1}$ As Peterson noted, ${ }^{9}$ the determinants of occupational stress, and the same holds for other work environment related health conditions, can be analysed at three levels: the job (nature of the work itself, including job design, break up of tasks, skill discretion, etc), the organisational structure (management styles, supervision, communication, etc) and a third level operating beyond the organisation or enterprise, the macro or societal level (involving management, labour and state relations in determining conditions of work activity and employment policies). Preventive programmes should be developed at the three levels. Systematic reviews of strategies to reduce workplace absenteeism have been recently published. ${ }^{10}$ Even in the more developed countries, there is still a long way to go for the care and the improvement of workers' health and well being. In the meanwhile, research focused on the design and implementation of effective preventive actions is strongly needed.

ANA M GARCÍA

Department of Public Health, University of Valencia, Avda, Tarongers s/n, 46022 Valencia, Spain (anagar@uv.es) 
1 Vahtera J, Kivimäki M, Pentti J, et al. Effect of change in the psychosocial work environment on sickness absence: a seven year follow up of initially healthy employees. F Epidemiol Community Health 2000;54:484-93.

3 Riihimäki H. Back and limb disorders. In: McDonald JC, ed. Epidemiology of Riihimäki $H$. Back and limb disorders. In: McDonald JC, ed. Epidemio.
work related diseases. London: BMJ Publishing Group; 1995:207-38.

4 Fernández JM. Financiación sanitaria, fraude, privatización y bajas laborales [Health financing, fraud, privatization and sickness absence]. Salud 2000 1998;67:8-9.

5 Moncada S, Manzanera R, Armengol R. La salud de los trabajadores y de sistema sanitario [Workers' health and health system's health]. Archivos de Prevención de Riesgos Laborales 1999;2:26-9.
6 Marmot MG, Bosma H, Hemingway $\mathrm{H}$, et al. Contribution of job control and other risk factors to social variations in coronary heart disease and other risk factors to social
incidence. Lancet 1997;350:235-9.

7 Davey-Smith G, Harding S. Is control at work the key to socioeconomic gradients in mortality? Lancet 1997;350:1369-70.

8 Hellerstedt WL, Jeffery RW. The association of job strain and health behaviours in men and women. Int f Epidemiol 1997;26:575-83.

9 Peterson CL. Work factors and stress: a critical review. Int $\mathcal{f}$ Health Serv 1994;24:495-519.

10 Gründemann RWM, van Vuuren CV. Preventing absenteeism at the workplace. Luxembourg: Office for Official Publications of the European Communities; 1997 